\title{
Predicting the Seasonal NDVI Change by GIS Geostatistical Analyst and Study on Driver Factors of NDVI Change in Hainan Island, China
}

\author{
Shaojun Liu, Bin Wang, Jinghong Zhang, Daxin Cai, \\ Guanhui Tian, Guofeng Zhang \\ South China Sea Meteorology and Disaster Mitigation Research Key Laboratory, Hainan Institute of \\ Meteorological Sciences, Haikou, China \\ Email: cdutlsj@163.com
}

Received 16 May 2016; accepted 12 June 2016; published 15 June 2016

Copyright (C) 2016 by authors and Scientific Research Publishing Inc.

This work is licensed under the Creative Commons Attribution International License (CC BY). http://creativecommons.org/licenses/by/4.0/

(c) (i) Open Access

\section{Abstract}

As Hainan Island belonged to tropical monsoon influenced region, vegetation coverage was high. It is accessible to acquire the vegetation index information from remote sensing images, but predicting the average vegetation index in spatial distributing trend is not available. Under the condition that the average vegetation index values of observed stations in different seasons were known, it was possible to qualify the vegetation index values in study area and predict the NDVI (Normal Different Vegetation Index) change trend. In order to learn the variance trend of NDVI and the relationships between NDVI and temperature, precipitation, and land cover in Hainan Island, in this paper, the average seasonal NDVI values of 18 representative stations in Hainan Island were derived by a standard 10-day composite NDVI generated from MODIS imagery. ArcGIS Geostatistical Analyst was applied to predict the seasonal NDVI change trend by the Kriging method in Hainan Island. The correlation of temperature, precipitation, and land cover with NDVI change was analyzed by correlation analysis method. The results showed that the Kriging method of ARCGIS Geostatistical Analyst was a good way to predict the NDVI change trend. Temperature has the primary influence on NDVI, followed by precipitation and land-cover in Hainan Island.

\section{Keywords}

NDVI, GIS Geostatistical Analyst, MODIS, Driving Factors, Correlation Coefficients 


\section{Introduction}

During the last years, powerful and versatile geostatistical tools have been developed for geoscience applications. Geostatistics is a methodology for incorporating the spatial and temporal coordinates of observations in data processing [1]. The applications of geostatistics have spread from the original metal mining topics to more diverse fields such as soil science, oceanography, hydrogeology, agriculture, and environmental science [2]. Recently GIS has emerged as an innovative and important component of many projects; the Geostatistical Analyst represents a major step in bridging the gap between GIS and geostatistics. ArcGIS Geostatistical Analyst is an extension to ArcGIS Desktop (ArcInfo, ArcEditor, and ArcView) that provides a variety of tools for spatial data exploration, anomaly identification, optimum prediction, uncertainty evaluation, and surface creation. ArcGIS Geostatistical Analyst is a complete package for spatial data preprocessing, geostatistical analysis, contouring, and post-processing. It also includes interactive graphical tools with robust parameters for default models to help newcomers to create prediction and standard errors. In the present study, the NDVI predicting was accomplished by the ArcGIS Geostatistical Analyst model. Geostatistical Analyst model can generate optimal surfaces from sample data and evaluate predictions for better decision making. It will be a good way to predict the Seasonal NDVI Change in Hainan Island.

The vegetation overcast was high and the change is not obvious in tropical region. NDVI is sensitive to the vegetation's growth condition, productivity and other biophysical and biochemical characters, so the change of NDVI can reflect the vegetation's growth conditions [3]-[5]. The spatial variance of vegetation is complex and ubiquity; in order to learn the variance trend of NDVI in a region, a new method was required to quantify the NDVI values analysis. If the average NDVI value of every station in different seasons was known, it was possible for us to qualify the NDVI value, and the predicting of NDVI change trend can be carried out. ArcGIS Geostatistical Analyst was applied to analyze the seasonal NDVI change trend by the Kriging method, based on the MODIS data of limited NDVI values.

The spectral characteristics of green leaves are highly absorptive of energy in visible blue, yellow, and red wavelengths (0.4 - 0.5, $5.7-0.7$ microns) of the electromagnetic spectrum, but highly reflective in the near infrared wavelengths (0.7 - 1.1 microns). Spectral responses of vegetation are further modified based on the leaf density and structure of the canopy. The relative differences in red (RED) and near infrared (NIR) spectral characteristics form the basis of several vegetation indices, which are designed to assess the condition of vegetation. The Normalized Difference Vegetation Index (NDVI), is expressed as

$$
\text { NDVI }=\frac{\mathrm{Pn}-\mathrm{Pr}}{\mathrm{Pn}+\mathrm{Pr}} \times 100 .
$$

Pn and Pr represent the near infrared (NIR) and red spectral reflectance values respectively. NDVI is a good indicator of the ability for vegetation to absorb photo synthetically active radiation. Environmental factors such as soil, geomorphology and vegetation can influence NDVI values.

NDVI data are derived from visible and near-infrared data acquired by the MODIS (Terra and Aqua platforms). Vegetation can influence the energy balance of earth-atmosphere, which plays an important role in climate, water, biochemistry cycles, and the sensitive indexes to climate and human dimension [6]. NDVI is figured out by the reflect bands which can reflect the growing situation of vegetation indirectly, so it was widely used in quantified research. As relationships between NDVI and climatic factors depend on location, more detailed analyses are needed for a variety of regions for a better understanding of temporal variation of precipitation and temperature [7]. Precipitation and temperature directly influence water balance, causing changes in soil moisture regime which in turn influences plant growth. In different areas, the indexes will lead to different roles in effecting the NDVI [8]. The variability of NDVI in temporal and space distribution not only is the result of climate but also leads to sensitive respond to short time climate fluctuate. Therefore, using the temperature, precipitation, and land-cover to discuss the relation of NDVI in Hainan Island is useful to confirm the influenced role on vegetation index change, which will benefit to study the relationship between vegetation with climate change.

This study addressed two key questions. Firstly, ArcGIS Geostatistical Analyst was applied to predict the seasonal NDVI change trend by the Kriging method in Hainan Island and check the predicting method. Secondly, the correlation of temperature, precipitation, and land cover with NDVI change was explored and discussed. 


\section{Data and Methods}

\subsection{Study Area}

Hainan Island belongs to tropical monsoon region. Tropical marine monsoon with plenty of sunshine, moderate rainfall. Annual average temperature $22.9^{\circ} \mathrm{C}$ whereas $20^{\circ} \mathrm{C}$ in winter. The hottest month is August, with a $29.5^{\circ}$ average. Hainan Island, also known as Qiong, is the second largest island in China with an area of 34,000 square kilometers, including 18 cities.

\subsection{Data}

MODIS images of 2004 were acquired by the Terra and aqua satellites. The images were downloaded from the NASA Earth Observing System Data Gateway free access server. MODIS is a new generation Imaging Spectroradiometer, which has moderate spectral resolution with 36 spectral bands that cover the wavelength range from 0.4 to $14 \mathrm{Am}$, and three spatial resolutions of 250, 500, and $1000 \mathrm{~m}$, respectively, and a swath of $2330 \mathrm{~km}$ [9].

\subsection{Methods}

MODIS surface reflectance for the visible near infrared wavelengths were corrected for atmospheric effects at the data centre using a bidirectional reflectance distribution function. For conform the national geo-database of China, we transformed MODIS images from ISIN to UTM WGS 84 coordinate system using the MODIS reprojection tool. In this study a standard 10 day composite NDVI generated from MODIS imagery was used. By far the most extended method for multitemporal compositing is the Maximum Value Composite (MVC) [10], which is computed by selecting the image values of the day when the Normalized Difference Vegetation Index (NDVI) is maximum in the time series. This criterion is simple to calculate and has been proven very useful for monitoring vegetation cover all over the earth [11]-[14]. The NDVI was also used to test the sensitivity differences between two indexes. NDVI was developed to optimize the vegetation signal with improved sensitivity in high biomass regions and improved vegetation monitoring through a de-coupling of the canopy background signal and a reduction in atmosphere influences [15].

The Kriging method of ARCGIS Geostatistical Analyst was applied to predict the change range of NDVI with an external drift (KED) [16]. Geostatistics is concerned with a variety of techniques aimed at understanding and modeling spatial variability through prediction and simulation [17] [18]. Geostatistics exploits the presence of spatial auto-correlation and joint dependence in space and time that occur in most natural resource variables [19]. KED is a variant of kriging allowing the use of secondary information known at every location (exhaustive), which is assumed to reflect the local spatial trend of the primary variable [16]. KED simulates the trend under the assumptions of a linear relationship between primary and secondary variables in the secondary variable. The algorithm of KED employs a non-stationary random function model, where stationarity is limited within each search neighborhood, yielding more local detail than ordinary kriging [17]. The KED estimator is:

$$
Z_{\mathrm{KED}}^{*}(u)=\sum_{a=1}^{n(u)} \lambda_{a}^{\mathrm{KED}}(u) Z\left(u_{a}\right) .
$$

$Z_{\mathrm{KED}}^{*}(u)$ is the KED estimator at location $u, \lambda_{a}^{\mathrm{KED}}(u)$ are the KED weights corresponding to the $n$ samples at location $u$, and $Z\left(u_{a}\right)$ are the sample values within the search neighborhood [16].

The relations between temperature, precipitation, land cover and NDVI were calculated by correlation analysis method.

\section{Result}

\subsection{Measured NDVI}

2004 was one of most severe drought year in Hainan Island. The NDVI satellite-derived information on vegetative cover was by the method maximum value composite (MVC), which is computed by selecting the image values of the day when the normalized difference vegetation index (NDVI) is maximum in the time series. So the seasonal average NDVI values were computed by maximum value composite (MVC) methods, firstly the 10 day NDVI values of every month were collected, then all pixes imagery mean NDVI values included in every 
stations region range of Hainan Island were computed, finally the average NDVI in every seasons were computed (Table 1).

\subsection{Predicting NDVI Trend}

The Kriging model was the best linearity and correctitude method, which was regarded as the most Exactly way in spatial data predicting and simulating and analyzing [20] [21]. Based on the NDVI values of 18 stations in Hainan Island, the trend of four seasonal predicting values were given (Figure 1).

From the predicting picture, the NDVI value of north of island is low, but the middle of island is high, south of island was in sequence. The NDVI variance in south is not obvious, the value is about $40-45$, the middle city-wuzhishan city is the highest value in the whole island, especially in third season (Jul to Sep). In the north city the value increase from Jan to Sep, but decrease from Oct to Dec, the mean NDVI value in the whole year was still low.

\subsection{Comparison of the Measured and Predicted NDVI Values}

In order to check up the method reliance in predicting NDVI value in Hainan Island, it is necessary to compare the predicting value with the measured value in January to March based on selectively eighteen stations. The measured values were acquired by the way in maximum value composite (MVC) and the predicting values were

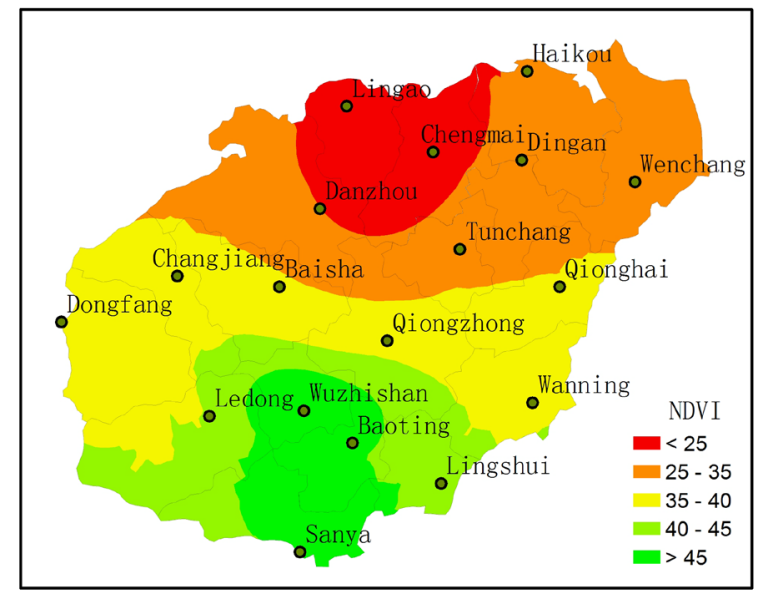

(a)

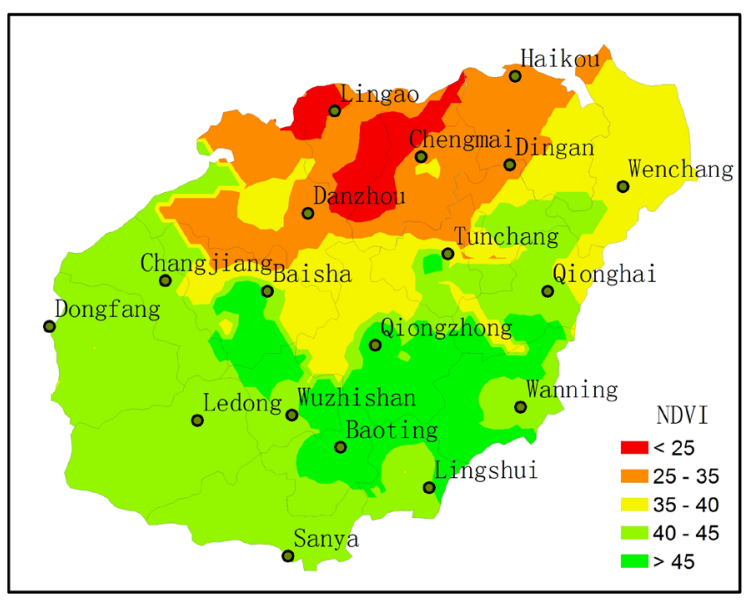

(c)

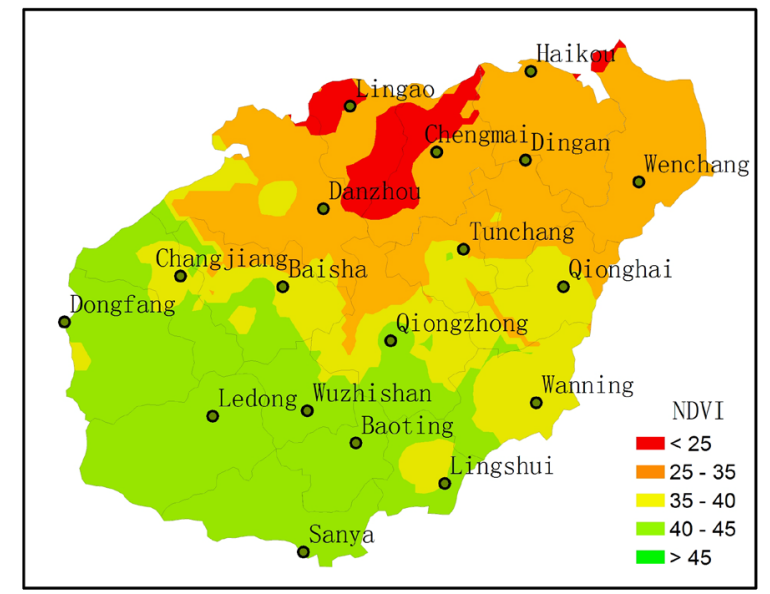

(b)

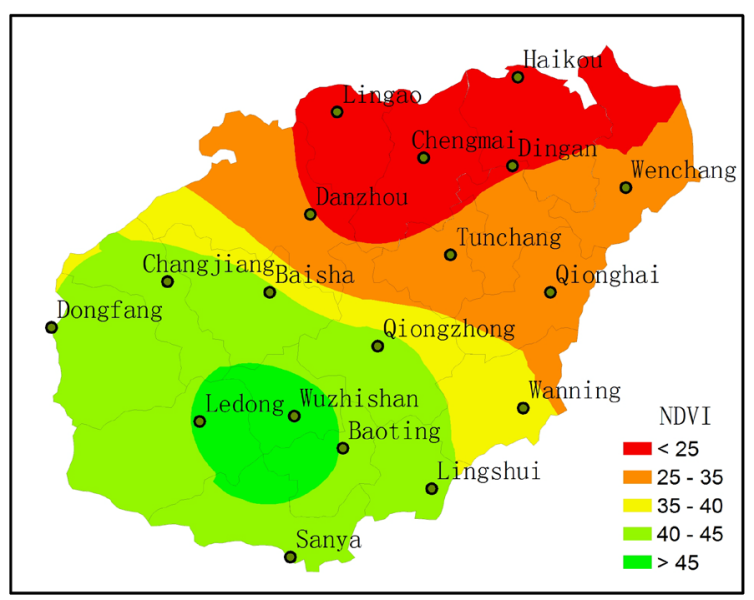

(d)

Figure 1. Predicted NDVI range of four quarters in Hainan Island. (a) January to March; (b) Apr to Jun; (c) Jul to Sep; (d) Oct to Dec. 
Table 1. Mean NDVI of 2004 in Hainan Island.

\begin{tabular}{|c|c|c|c|c|}
\hline Stations & January to March & Apr to Jun & Jul to Sep & Oct to Dec \\
\hline Haikou & 27.3 & 29.2 & 35.6 & 22.0 \\
\hline Wenchang & 30.7 & 30.6 & 34.3 & 21.7 \\
\hline Qionghai & 39.0 & 39.0 & 43.3 & 31.0 \\
\hline Wanning & 41.3 & 37.0 & 42.3 & 34.7 \\
\hline Linshui & 39.0 & 39.3 & 40.3 & 36.0 \\
\hline Sanya & 42.3 & 44.3 & 41.0 & 44.3 \\
\hline Ledong & 38.3 & 42.7 & 40.7 & 44.0 \\
\hline Dongfang & 36.3 & 41.3 & 40.7 & 39.7 \\
\hline Changjian & 40.3 & 39.7 & 42.3 & 40.3 \\
\hline Danzhou & 31.7 & 38.3 & 41.0 & 33.7 \\
\hline Lingao & 27.0 & 34.7 & 36.3 & 26.7 \\
\hline Chengmai & 30.3 & 35.7 & 38.0 & 27.0 \\
\hline Dingan & 29.7 & 34.7 & 42.0 & 27.0 \\
\hline Tunchang & 36.7 & 41.3 & 48.3 & 33.0 \\
\hline Qiongzhoung & 44.7 & 44.6 & 51.3 & 44.7 \\
\hline Baisha & 42.7 & 43.3 & 51.0 & 46.7 \\
\hline Wuzhishan & 48.7 & 42.0 & 43.3 & 50.3 \\
\hline Baoting & 45.0 & 43.7 & 47.0 & 47.7 \\
\hline
\end{tabular}

counted by Kriging interpolation model in ArcGIS Geostatistical Analyst. The measured values, predicting values and standardized error equation were shown in Figure 2 and Figure 3. Measured values and predicting values equation pass the f-test way, and the error range between in $0.7 \%-20 \%$. This indicated that Kriging interpolation model in ArcGIS Geostatistical Analyst can content with the need in NDVI predicting.

\subsection{Analysis of Driver Factors of NDVI}

Variations of NDVI are closely linked with precipitation. There is a strong linear [22] or log-linear [23] relationship between NDVI and precipitation in cases where monthly or seasonal precipitation is within a certain range. Variations in climatic factors, in particular precipitation and temperature, have a strong influence on variation in NDVI for a given site [7]. The NDVI satellite-derived information on vegetative cover had revealed large seasonal fluctuations in the spatial extent and vigor of land vegetation caused largely by seasonal precipitation variations.

In different areas, the indexes will lead to different roles affecting the NDVI [8]. The variability of NDVI in temporal and spatial distribution is not only result of climate but also lead to sensitive respond to short time climate fluctuated. Therefore, using the temperature, precipitation, land-cover to discuss the relation of NDVI in Hainan Island is useful to determine the role index, which will benefit to studying the relationship between vegetation with climate change.

As the relationships between NDVI and temperature, precipitation, land cover depend upon location, more detailed analysis are needed for a variety of regions to better understand temporal variation of temperature, precipitation and land cover. For consideration the Hainan Island located in the tropical area, the land-cover variance was not obvious during the whole year. So this factor was not taken as main factor. Temperature and precipitation were two main factors to influence the variance of NDVI. By the analysis on relations between average NDVI and average temperature (Figure 4) and relations between average NDVI and average precipitation (Figure 5) in selectively seven stations, the correlation coefficients were acquired (Table 2). 


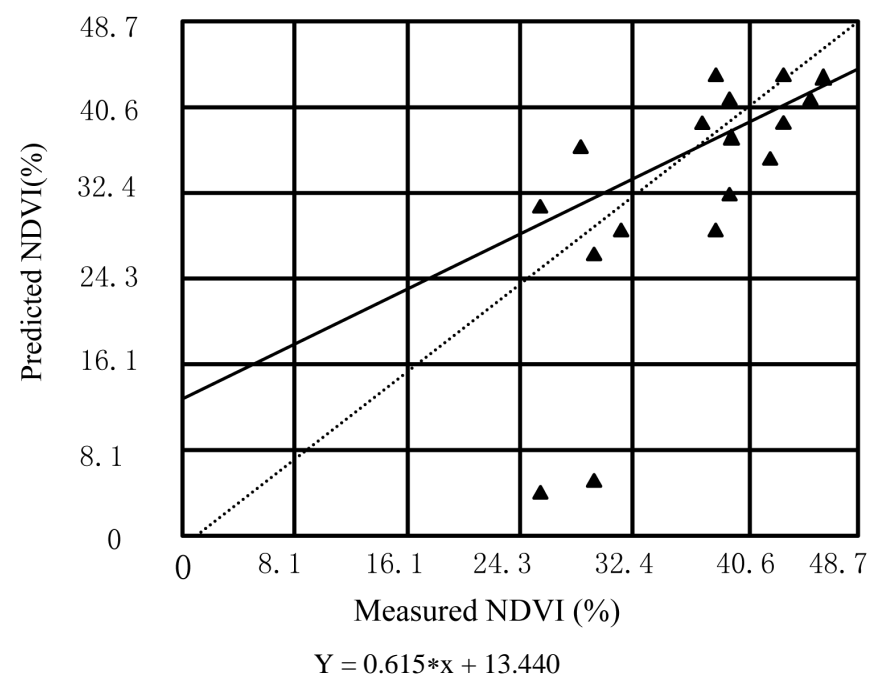

Figure 2. Measured and predicted NDVI value.

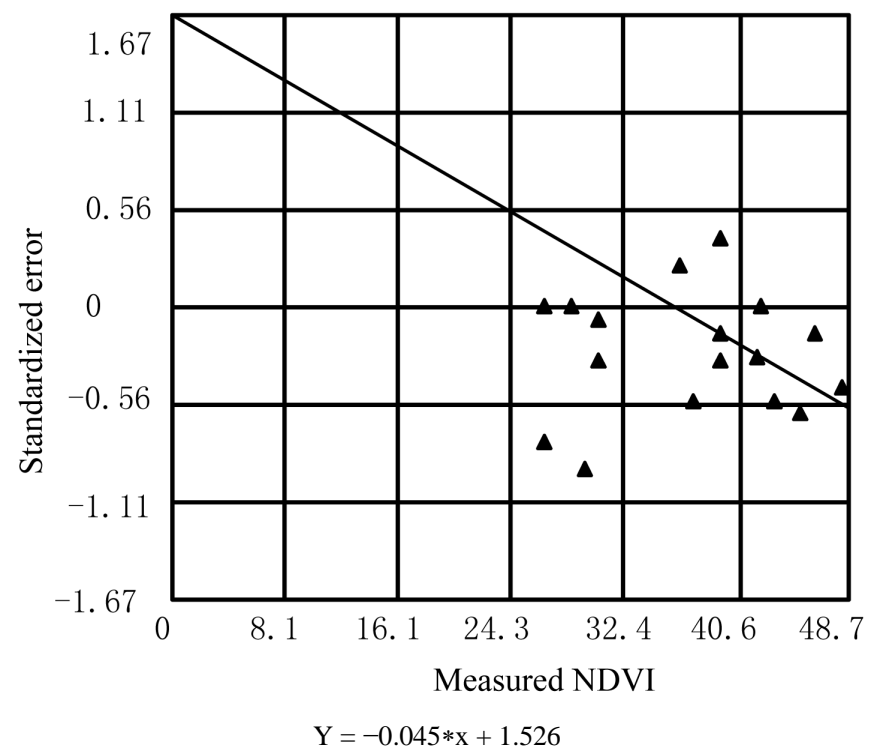

Figure 3. Measured and standardized error NDVI value.

Table 2. The correlation coefficients of monthly average temperature, precipitation with NDVI.

\begin{tabular}{ccccc}
\hline \multirow{2}{*}{ Study area } & \multicolumn{2}{c}{ Monthly temperature } & \multicolumn{2}{c}{ Monthly precipitation } \\
\cline { 2 - 5 } & Co-relation & F-test & Co-relation & F-test \\
Haikou & 0.63 & 4.36 & 0.44 & 0.0110 \\
Danzhou & 0.72 & 2.98 & 0.42 & 0.0024 \\
Qionghai & 0.61 & 3.88 & 0.05 & 0.0089 \\
Qiongzhong & 0.57 & 3.86 & 0.42 & 0.0040 \\
Dongfang & 0.35 & 3.48 & 0.01 & 0.0032 \\
Lingshui & 0.36 & 5.02 & 0.02 & 0.0094 \\
Sanya & 0.47 & 4.31 & 0.32 & 0.0039 \\
\hline
\end{tabular}




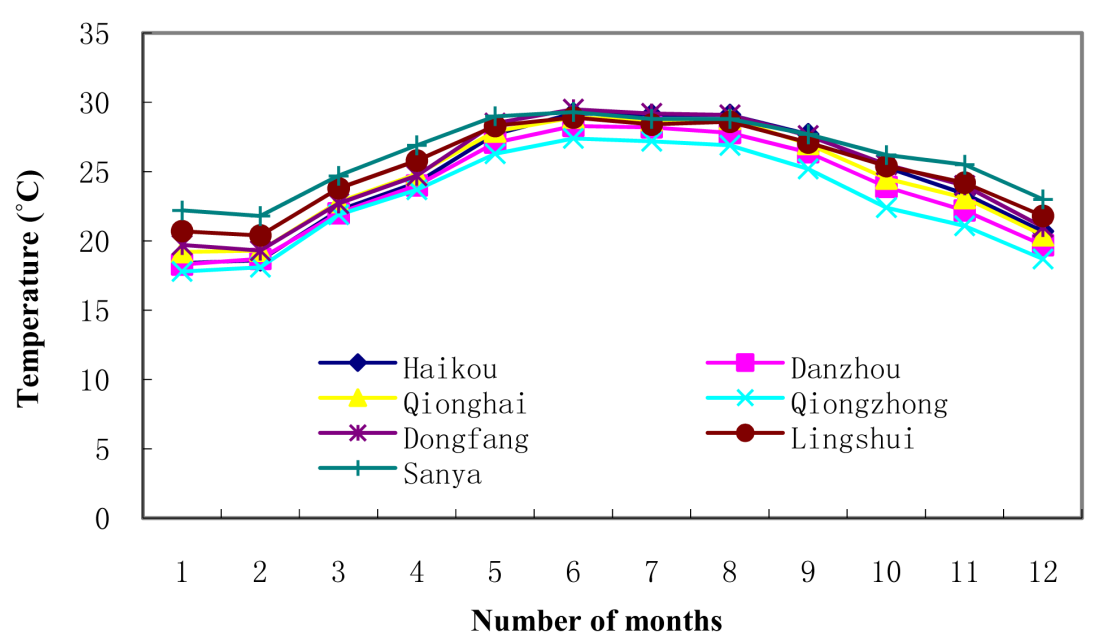

Figure 4. Monthly average temperature of Hainan Island in 2004.

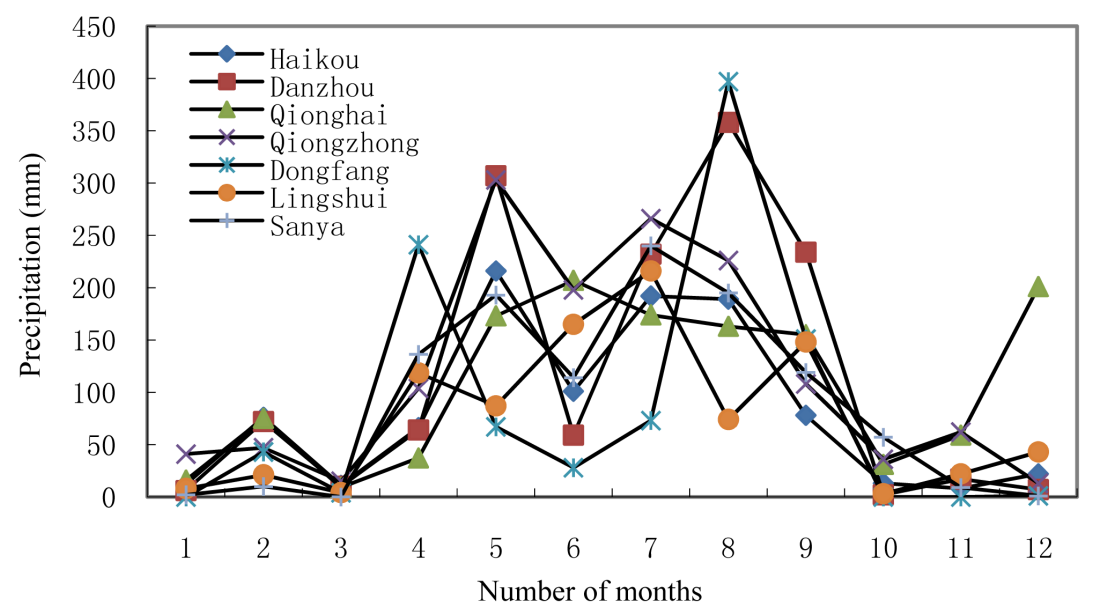

Figure 5. Monthly precipitation of Hainan Island in 2004.

The results also show that temperature is an important factor for plant growth, but its variation is a contributing factor only at specific times of the growing season. Within season analyses show strongly correlation between NDVI and temperature indices. In Table 2, the result can be drawn that relations between temperature and NDVI is significant and the co-relation values passed the F-test, $\mathrm{a}=0.05$.

Relations between precipitation and NDVI was not obvious and failed the F-test, $\mathrm{a}=0.05$. Correlation coefficients between precipitation and NDVI varied depending upon combinations of time duration and time lag, and also early, middle or late growing season, whereas cropland correlation coefficients were intermediate, and correlations for forests were weakest. Correlation coefficients for additional combinations of duration and lag were not calculated because preliminary analysis of a subset of combinations showed that only the immediate two periods of temperature were significantly related to NDVI [7].

Temperature was more significant to influence NDVI than precipitation. Temperature will be the main driver factor to NDVI, followed by precipitation, land-cover.

\section{Discussion and Conclusions}

There were many ways to derive vegetation index from remote sensing image such as, Normal Different Vegetation Index (NDVI), Ratio Vegetation Index (RVI), Difference Vegetation Index (DVI), Soil-Adjusted Vegetation Index (SAVI), and Modified Soil-Adjusted Vegetation Index (MSAVI). Hainan Island belongs to tropical area; vegetation-cover change is not distinctness within different seasons. But Normal Different Vegetation In- 
dex (NDVI) was sensitive to vegetation growth situation; therefore this NDVI way was chosen to derive vegetation index of different seasons in all stations in Hainan Island. In order to quantity the vegetation condition, it is necessary to learn the average NDVI values in different stations, which support the data for the next predicting NDVI values in whole island.

ArcGIS Geostatistical Analyst combined by GIS and Geostatistics was applied to analyze the seasonal NDVI change trend by the Kriging method based on the MODIS data in Hainan Island, which was compared with the measured NDVI in January to March; the result indicated that the Kriging method of ARCGIS Geostatistical Analyst was a good way to predict the NDVI change trend.

Temperature, precipitation, and land-cover are the main factors which influence the change of vegetation index and the impact is not same in different regions. On the basis of vegetation index derived from MODIS imagery, the driving factors of temperature, precipitation, and land-cover were analyzed by correlation analysis method. Correlation coefficients between temperature and NDVI were significant and the correlation coefficients passed the F-test, $\mathrm{a}=0.05$. Correlation coefficients between precipitation and NDVI failed the F-test, $\mathrm{a}=$ 0.05 . The changes of vegetation index were primarily influenced by temperature, followed by precipitation and land-cover in Hainan Island.

\section{Acknowledgements}

The research work was supported by National Natural Science Foundation of China under Grant No.41465005, 41175096, 41265007 and Natural Science Foundation of Hainan Provincial under Grant No. 20154172, 409005. The writers are grateful for the support.

\section{References}

[1] Houlding, S.W. (2000) Practical Geostatistics-Modeling and Spatial Analysis. Springer, New York.

[2] Berke, O. (2004) Exploratory Disease Mapping: Kriging the Spatial Risk Function from Regional Count Data. International Journal of Health Geographics, 3, 18. http://dx.doi.org/10.1186/1476-072X-3-18

[3] Zhang, Y.-D., Xu, Y.-T., Gu, F.-X. and Pan, X.-L. (2003) Correlation Analysis of NDVI with Climate and Hydrological Factors in Oasis and Desert. Acta Phytoecologica Sinica, 27, 816-821. (In Chinese) http://dx.doi.org/10.17521/cjpe.2003.0117

[4] Hall, F.G., Townshend, J.R. and Engman, E.T. (1995) Status of Remote Sensing Algorithms for Estimation of Land Surface State Parameters. Remote Sensing of Environment, 51, 138-156. http://dx.doi.org/10.1016/0034-4257(94)00071-T

[5] Walther, G.R., Post, E. and Convey, P. (2002) Ecological Responses to Recent Climate Change. Nature, 416, 389-395. http://dx.doi.org/10.1038/416389a

[6] Guo, N. (2003) Vegetation Index and Its Advances. Arid Meteorology, 24, 71-75. (In Chinese)

[7] Wang, J., Rich, P.M. and Price, K.P. (2003) Temporal Responses of NDVI to Precipitation and Temperature in the Central Great Plains, USA. International Journal of Remote Sensing, 24, 2345-2364. http://dx.doi.org/10.1080/01431160210154812

[8] Gao, Z.-Q. and Liu, J.-Y. (2000) The Study on Driving Factors and Models of NDVI Change Based on Remote Sensing and GIS in China. Climatic and Environmental Research, 5, 155-164. (In Chinese)

[9] Tang, J.K., Xue, Y., Yu, T. and Guan, Y.N. (2005) Aerosol Optical Thickness Determination by Exploiting the Synergy of TERRA and AQUA MODIS. Remote Sensing of Environment, 94, 327-334. http://dx.doi.org/10.1016/j.rse.2004.09.013

[10] Holben, B.N. (1986) Characteristics of Maximum-Value Composite Images from Temporal AVHRR Data. International Journal of Remote Sensing, 7, 1417-1434. http://dx.doi.org/10.1080/01431168608948945

[11] Illera, P., Fernández, A. and Delgado, J.A. (1996) Temporal Evolution of the NDVI as an Indicator of Forest Fire Danger. International Journal of Remote Sensing, 17, 1093-1105. http://dx.doi.org/10.1080/01431169608949072

[12] Kasischke, E. and French, N.H. (1995) Locating and Estimating the Area Extent of Wildfires in Alaskan Boreal Forest Using Multiple-Season AVHRR NDVI Composite Data. Remote Sensing of Environment, 51, 263-275. http://dx.doi.org/10.1016/0034-4257(93)00074-J

[13] Peters, A.J., Walter-Shea, E.A., Ji, L., Viña, A., Hayes, M. and Svodoba, M.D. (2002) Drought Monitoring with NDVI-Based Standardized Vegetation Index. Photogrammetric Engineering and Remote Sensing, 62, 71-75.

[14] Potter, C.S. and Brooks, V. (2000) Global Analysis of Empirical Relations between Annual Climate and Seasonality of 
NDVI. International Journal of Remote Sensing, 19, 2921-2948. http://dx.doi.org/10.1080/014311698214352

[15] Huete, A., Justice, C. and van Leeuwen, W. (1999) MODIS Vegetation Index (MOD13) Algorithm Theoretical Basis Document, Version 3.

[16] Berterretche, M., Hudak, A.T. and Cohen, W.B. (2005) Comparison of Regression and Geostatistical Methods for Mapping Leaf Area Index (LAI) with Landsat ETM+ Data over a Boreal Forest. Remote Sensing of Environment, 96, 49-61. http://dx.doi.org/10.1016/j.rse.2005.01.014

[17] Deutsch, C. (2002) Geostatistical Reservoir Modeling. Oxford University Press, New York.

[18] Journel, A. (1989) Fundamentals of Geostatistics in Five Lessons. American Geophysical Union, Washington DC. http://dx.doi.org/10.1029/SC008

[19] Myers, J. (1997) Geostatistical Error Management: Quantifying Uncertainty for Environmental Sampling and Mapping. New York Van No Strand Rein Hold.

[20] Webster, R. and Oliver, M.A. (1990) Geostatistics for Environmental Scientists. John Wiley \&Sons, Ltd., West Sussex, 84-90.

[21] Shi, Z., Jin, H.-M., Li, Y. and Li, H.-Y. (2005) Development and Application of Soft Package for Geostatistics. Journal of Soil Water Conservation, 19, 170-173. (In Chinese)

[22] Malo, A.R. and Nichloson, S.E. (1990) A Study of Rainfall and Vegetation Dynamics in the African Sahel Using Normalized Difference Vegetation Index. Journal of Arid Environments, 19, 1-24.

[23] Davenport, M.L. and Nichloson, S.E. (1993) On the Relation between Rainfall and the Normalized Difference Vegetation Index for Diverse Vegetation Types in East Africa. International Journal of Remote Sensing, 14, 2369-2389. http://dx.doi.org/10.1080/01431169308954042

\section{Submit or recommend next manuscript to SCIRP and we will provide best service for you:}

Accepting pre-submission inquiries through Email, Facebook, Linkedin, Twitter, etc A wide selection of journals (inclusive of 9 subjects, more than 200 journals)

Providing a 24-hour high-quality service

User-friendly online submission system

Fair and swift peer-review system

Efficient typesetting and proofreading procedure

Display of the result of downloads and visits, as well as the number of cited articles

Maximum dissemination of your research work

Submit your manuscript at: http://papersubmission.scirp.org/ 